\title{
Alternative Non-Ionic Pathway for Uncatalyzed Prins Cyclization: DFT Approach
}

\author{
Rodolfo G. Fiorot, ${ }^{(a, b}$ Gottimukkala Rambabu, ${ }^{c}$ Vijayaparthasarathi Vijayakumar, ${ }^{d}$ \\ Yarragudi B. Kiran ${ }^{\circledR c}$ and José W. M. Carneiro ${ }^{\circledR} * b$ \\ aInstituto Federal de Educação, Ciências e Tecnologia do Rio de Janeiro, \\ 21715-000 Rio de Janeiro-RJ, Brazil \\ ${ }^{b}$ Instituto de Química, Universidade Federal Fluminense, 24020-141 Niterói-RJ, Brazil \\ ${ }^{c}$ Department of Chemistry, Sree Vidyanikethan Engineering College, \\ 517102 A Rangampet, Tirupati, India \\ ${ }^{d}$ Centre for Organic and Medicinal Chemistry, VIT University, \\ 632014 Vellore, Tamil Nadu, India
}

\begin{abstract}
Density functional theory calculations $(\omega \mathrm{B} 97 \mathrm{X}-\mathrm{D} / 6-311++\mathrm{G}(\mathrm{d}, \mathrm{p}))$ are employed to investigate an alternative pathway for Prins-like cyclization. Although strong acids usually catalyze this reaction, 4-amino-1,3-dioxanes are rapidly obtained in high yields without catalyst when benzenamines and acetaldehyde react at low temperatures, in aqueous medium. Considering these conditions, we applied a supermolecule model with explicit water molecules to compute the mechanism for 4-amino-1,3-dioxanes formation from the reactants. The structure of the primary solvation shell was determined by Metropolis Monte Carlo method. In the Prins-cyclization step, we found an unpredicted pathway with non-ionic transition structures or intermediates. Explicit water molecules establish a net of hydrogen bonds allowing prototropism, maintaining the electrical neutrality in the system while two protons transfer occurs. To provide data to further experimental confirmation of this hypothesis, we estimated the kinetic isotope effect for the reaction. We also investigated the use of aliphatic amines, which indicates that the reaction may be of a broader application than first observed experimentally.
\end{abstract}

Keywords: reaction mechanism, supermolecule model, Prins cyclization, dioxanes, DFT

\section{Introduction}

1,3-Dioxanes are six-membered rings formed by four carbon and two oxygen atoms in relative positions 1,3. They are found in many natural products and semi-synthetic derivatives presenting diverse bioapplications. ${ }^{1}$ These heterocycles are also employed as solvents and protective groups in multistep organic synthesis. ${ }^{2}$ Synthetic 1,3-dioxanes ${ }^{3}$ and their five-membered ring analogues, 1,3-dioxolanes, ${ }^{4}$ have also been produced aiming compounds with biological activity such as analgesic, ${ }^{5}$ anesthesic, ${ }^{6}$ anti-inflammatory ${ }^{7}$ and multidrug resistance modulator. ${ }^{8}$

These important heterocycles are classically synthesized by Prins cyclization: a condensation between alkenes and aldehydes under strong acid catalysis. Formerly, this type of

*e-mail: jose_walkimar@id.uff.br condensation was made by Kriewitz in 1899 and 20 years later Prins ${ }^{10,11}$ published a comprehensive set of works of the reaction between formaldehyde and unsaturated hydrocarbons. This powerful methodology for formation of $\mathrm{C}-\mathrm{C}$ bonds is also useful to produce substances such as 1,3-diol, $\beta$-halohydrin, allylic alcohols and tetrahydropyran (Scheme 1). ${ }^{12}$

Control of experimental conditions is extremely important to reach the desired product with high selectivity. 1,3-Dioxanes, for example, can be synthesized with an excess of suitable aldehyde in presence of an acid catalyst. ${ }^{12}$ It has been well established that either strong Lewis (e.g., $\left.\mathrm{TiCl}_{4}, \mathrm{TiBr}_{4}, \mathrm{InCl}_{3}, \mathrm{SnCl}_{4}, \mathrm{BF}_{3} . \mathrm{OEt}_{2}\right)^{13-18}$ or Brønsted acids (e.g., $\mathrm{H}_{2} \mathrm{SO}_{4}$, trifluoroacetic acid, $p$-toluenesulfonic acid, triflic acid) ${ }^{19-22}$ have to be employed to the effective synthesis of these heterocycles. Some studies have demonstrated that concomitant usage of both types of acid catalysts has positive synergistic effect. ${ }^{23,24}$ However, some 


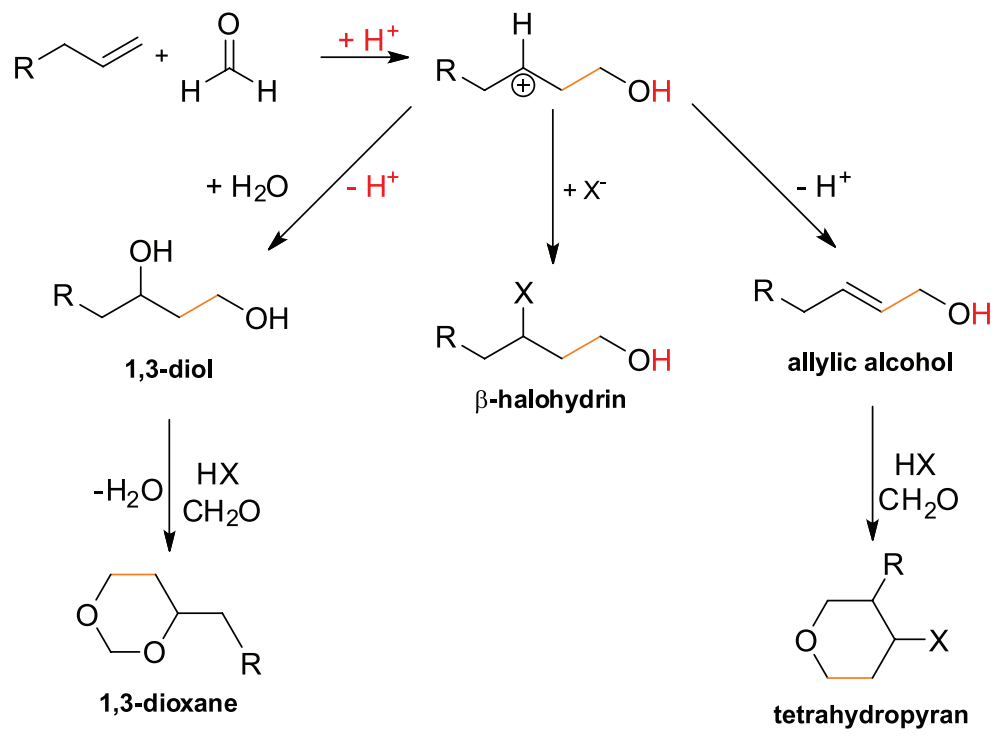

Scheme 1. Classical Prins reaction under acid catalysis and the possible product distribution, depending on the experimental conditions.

of these methodologies require tedious procedures, like low temperature (e.g., $-78^{\circ} \mathrm{C}$ ), to preserve the catalytic cycle of the acid. ${ }^{13}$

Computational studies have been done to rationalize the formation of 1,3-dioxanes via Prins cyclization, as well as to justify the chemo-, regio- and stereoselectivity. ${ }^{12,25,26}$ The mechanism of the classical Prins reaction has usually been supposed to pass through cationic species, such as carbocations, mainly in aqueous media. Recently, Yamabe et al. ${ }^{27}$ warned that such ionic intermediates might not be found in the minimum energy path in presence of water, suggesting a hemiacetal as an unprecedentedly less energetic new intermediate (Scheme 2).

Rambabu et $a l .{ }^{28}$ recently published the unexpected synthesis of 4-arylamino-1,3-dioxanes in a Prins-like cyclization in aqueous medium without any catalyst. Initially, 1,3-dioxane was isolated as a by-product ( $30 \%$ yield) of the Mannich reaction between benzenamine and acetaldehyde in presence of a $\beta$-ketoester. After optimizing the experimental conditions using three equivalents of the arylamine and suppressing the $\beta$-ketoester, the 1,3-dioxane yield enhanced to $85 \%$. This new route to 1,3 -dioxanes has proven to obey<smiles>[R]CC(=CCCCC(=O)O)CCOP</smiles>

a. Classical mechanism through carbocation

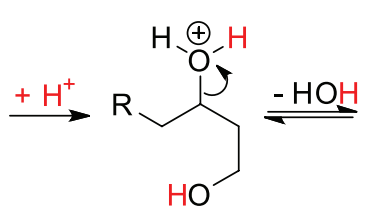<smiles>[R]C[C](CCO)CCO</smiles>

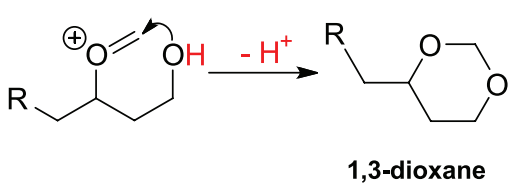

b. Mechanism through hemiacetal<smiles>CC([PH+])C=O</smiles><smiles>[R]CC1CCOCC[C@H](O)[C@@H](C)O1</smiles><smiles>C1=C[PH2+][CH+]1</smiles>

R

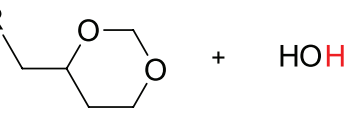

1,3-dioxane

Scheme 2. Mechanistic alternatives for Prins cyclization: (a) ionic intermediate passing through a carbocationic species; (b) neutral intermediate involving a hemiacetal. 
the green chemistry principles, since the desired product is obtained with no catalyst, under low temperatures $\left(0-5^{\circ} \mathrm{C}\right)$, non-tedious work-up, low reaction time, and high selectivity and yield.

Although a first suggestion on the reaction mechanism was attempted, ${ }^{28}$ it is necessary to gather more detailed information, particularly on the role of the solvent water in the kinetic and thermodynamic parameters of the reaction. With this aim, we mapped the reaction pathways from the starting materials, benzenamine and acetaldehyde, until formation of the 1,3-dioxane. As substituents in the benzene ring of benzenamine showed direct consequences on the reaction time, we also modeled the final cyclization step with $p$-nitrobenzenamine and $p$-methoxybenzenamine to check whether the same reaction profile is followed by these substituted benzenamines. Additionally, we also computed the reaction profile with an aliphatic amine (methylamine) to verify whether the reaction is restricted to aromatic amines, as studied experimentally.

\section{Methodology}

All quantum calculations were performed using the density functional theory (DFT) approach with the Gaussian09 software package ${ }^{29}$ and its default convergence criteria. Geometry optimizations and frequency calculations were carried out using the long-range corrected hybrid functional with empirical atom-atom dispersion corrections $\omega \mathrm{B} 97 \mathrm{X}-\mathrm{D}^{30}$ and the $6-311++\mathrm{G}(\mathrm{d}, \mathrm{p})$ basis set. ${ }^{31}$ The $\omega B 97 X-D$ functional has been employed to study systems where hydrogen bonds play a relevant role. . $^{32,33}$

We characterized the nature of the stationary points according to their second order Hessian matrix: minimum energy points on the potential energy surface showed only positive eigenvalues and transition states showed one and only one negative eigenvalue. Implicit solvation was considered in all steps with the self-consistent reaction field (SCRF) option of Gaussian09, using the integral equation formalism variant of the polarizable continuum model $(\text { IEFPCM })^{34,35}$ with water $(\varepsilon=78.35)$ as solvent.

Explicit microsolvation using the supermolecule model was employed to simulate the steps in which charged species and prototropism are involved. The assessment of the first solvation shell was accomplished by metropolis Monte Carlo method (MC), ${ }^{36}$ after computing the charge distribution using the CHELPG (charges from electrostatic potentials using a grid based method) procedure ${ }^{37}$ at the same calculation level. The MC simulations were carried out in a canonical (NVT) ensemble at $\mathrm{T}=298 \mathrm{~K}$ using the DICE software. ${ }^{38}$ One solute molecule and 999 water molecules were considered in the MC simulation. Lennard-
Jones potential parameters ( $\sigma$ and $\varepsilon$ ) were obtained from the OPLS-AA (optimized potentials for liquid simulationsall atom) force field. ${ }^{39}$ The number of water molecules of the first solvation shell were determined by the radial pair distribution, $g(r)$. The final arrangement including the solute and the first solvation shell molecules was then fully optimized under the $\omega$ B97X-D/6-311++G(d,p) level.

Thermodynamic parameters were computed at $298 \mathrm{~K}$ and $1 \mathrm{~atm}$, after frequency calculation in the default configuration, using standard statistical thermodynamic equations. ${ }^{40}$ Energy values for each step are reported as changes in enthalpy $\left(\Delta \mathrm{H}^{298}\right)$ and in the Gibbs free energy $\left(\Delta \mathrm{G}^{298}\right)$, both computed at $298 \mathrm{~K}$.

To find the transition states involving changes in more than one internal coordinate, e.g., the cyclization steps involving prototropism, it was necessary to perform a relaxed potential energy surface (PES) scan calculation varying two specific internal coordinates: the $\mathrm{C} \cdots \mathrm{O}$ distance for the forming $\mathrm{C}-\mathrm{O}$ bond, and the $\mathrm{O} \cdots \mathrm{H}$ distance for the $\mathrm{O}-\mathrm{H}$ bond involved in the proton transfer. The resulting points were plotted as a three-dimensional plot of energy as a function of the two internal coordinates, generating a topographic map, which helped identifying the saddle points. We also employed intrinsic reaction coordinate (IRC) analysis ${ }^{41}$ in these new proposed transition states in the default configurations, with a step length of $0.01 \mathrm{amu}^{1 / 2}$. For the cyclization step, we estimated the kinetic isotope effect (KIE) using the ISOEFF98 software ${ }^{42}$ for the three final candidates of transition structures, to provide data for an eventual experimental verification of the proposed mechanism.

\section{Results and Discussion}

The Results and Discussion section was divided into two parts: calculation of the energetic profiles for the reaction using the aromatic amines (benzenamine and its derivatives: $p$-nitrobenzenamine and $p$-methoxybenzenamine) and indication that this process is also energetically reasonable for aliphatic amines, such as methylamine $(\mathrm{R}=\mathrm{Me})$.

The mechanism of formation of 1,3-dioxanes using benzenamine $(R=P h)$

To rationalize the formation of 4-arylamino-1,3-dioxane, we started from the already suggested reaction mechanism, as shown in Scheme 3. ${ }^{28}$

Compatible with the experimental requirements to enhance the selectivity towards the 1,3-dioxane, the proposed mechanism shows the incorporation of 3 units of aldehyde per unit of arylamine. In step a, the amine attacks the first molecule of acetaldehyde, 

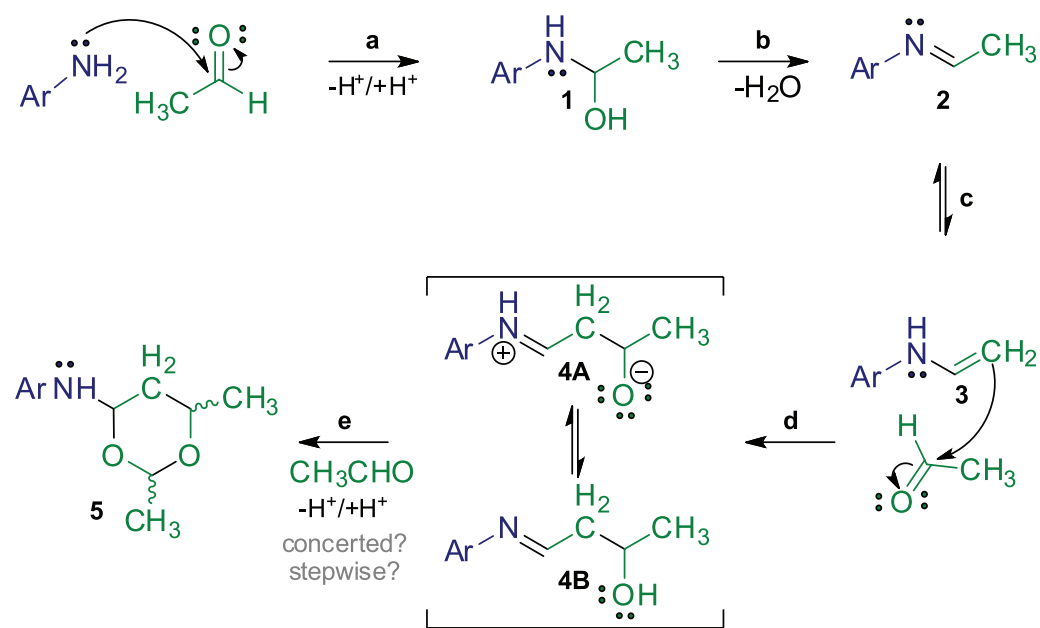

Scheme 3. Suggested reaction mechanism of formation of 4-arylamino-1,3-dioxane from benzenamine and formaldehyde. Steps: (a) formation of the alkanolamine (1); (b) formation of the imine (2); (c) imine-enamine tautomerism; (d) nucleophilic attack of enamine on a second unit of acetaldehyde; (e) Prins-like cyclization with the third unit of acetaldehyde.

yielding alkanolamine 1, after prototropism. In step b, elimination of one water molecule leads to the imine $\mathbf{2}$, which might undergo tautomerization (step c) to produce the nucleophilic enamine $\mathbf{3}$. Thus, $\mathbf{3}$ attacks the second unit of aldehyde to form the zwitterionic intermediate 4A in step d. However, we also considered a possibility that $4 \mathrm{~A}$ might be converted into a specie with no charge separation $\mathbf{4 B}$, even though zwitterions are stabilized in water solutions. Finally, $\mathbf{4 A}$ and/or $\mathbf{4 B}$ reacts with the third aldehyde molecule in a Prins-like cyclization (step e), leading to the desired product $\mathbf{5}$. Step e was examined carefully once it starts from 4A/4B and reacts concerted (as suggested by Rambabu et al. ${ }^{28}$ in the experimental study) or stepwise.

Initially, we looked for the relevant stationary points related to formation of the enamine (steps $a, b$ and c). Acids or bases usually catalyze the formation of alkanolamines. However, in their absence in aqueous media, prototropism may play an important role in the chemical equilibrium associated with the imine formation. ${ }^{43}$ Explicit microsolvation is encouraged to correctly model this step. Analysis of radial pair distribution g(r) (Figure S1, Supplementary Information (SI) section) given by Metropolis Monte Carlo calculation (MC) for the initial complex $\mathbf{I C}_{1}$ revealed 5 water molecules in the primary solvation shell surrounding benzenamine and acetaldehyde molecules. Thus, all optimizations of intermediates in these steps were carried out with these number and configuration of water molecules. This methodology has the advantage of giving information about the primary solvation shell in a statistical Boltzmann weighted manner.

Our results show that in the first step the initial complex $\mathbf{I C}_{\mathbf{1}}$ passes through a high energetic zwitterionic intermediate, $\mathbf{I n t}_{\mathbf{1}}$, to form the alkanolamine $\mathbf{1}$, in agreement with previous observations. ${ }^{43,44}$ In step $b$, dehydration leading to imine 2 is spontaneous, releasing $1.7 \mathrm{kcal} \mathrm{mol}^{-1}$. Tautomerization converts $\mathbf{2}$ into the enamine $\mathbf{3}$. Changes in enthalpy and Gibbs free energies for the minimum energy points are shown in Figure 1. Relative energy of the transition structure for the nucleophilic attack of benzenamine on acetaldehyde to form the zwitterionic intermediate, $\mathbf{T S}_{1}$, is also shown, with $1.967 \AA$ for the $\mathrm{N} \cdots \mathrm{C}$ forming bond length.

In the final optimized stationary points the solvent water molecules maintain the net of hydrogen bonds, less than $2 \AA$ distance, connected to the suitable sites of the reacting system (heteroatoms with non-bonded electrons and charged sites), allowing prototropism. It is important to highlight that the optimized structure of $\mathbf{I n t}_{\mathbf{1}}$ is not obtained without the net of water molecules explicitly solvating the charged sites. Anyways, even though $\mathbf{I n t}_{1}$ could be formed during the reaction course, it would be rapidly converted into its neutral form $\mathbf{1}$. The thermodynamic data show that the enamine $\mathbf{3}$ is $8 \mathrm{kcal} \mathrm{mol}^{-1}$ less stable than the imine $\mathbf{2}$, in agreement with previous results that show imines to be in general more stable than enamines. ${ }^{45}$ Once formed, the nucleophilic enamine $\mathbf{3}$ is able to attack a second aldehyde molecule, shifting the equilibrium towards the products. See SI section for optimized geometries including the solvating water molecules.

Following on the reaction path, we initially simulated step d considering only implicit solvation. The relative energy of the zwitterion $\mathbf{4}$ with respect to its initial complex $\mathbf{I C}_{4}$ is $27.3 \mathrm{kcal} \mathrm{mol}^{-1}$. For a reaction occurring at low temperatures, lower activation energy should be expected, however. This high relative energy changes dramatically when intermediate $\mathbf{4}$ is explicitly surrounded 


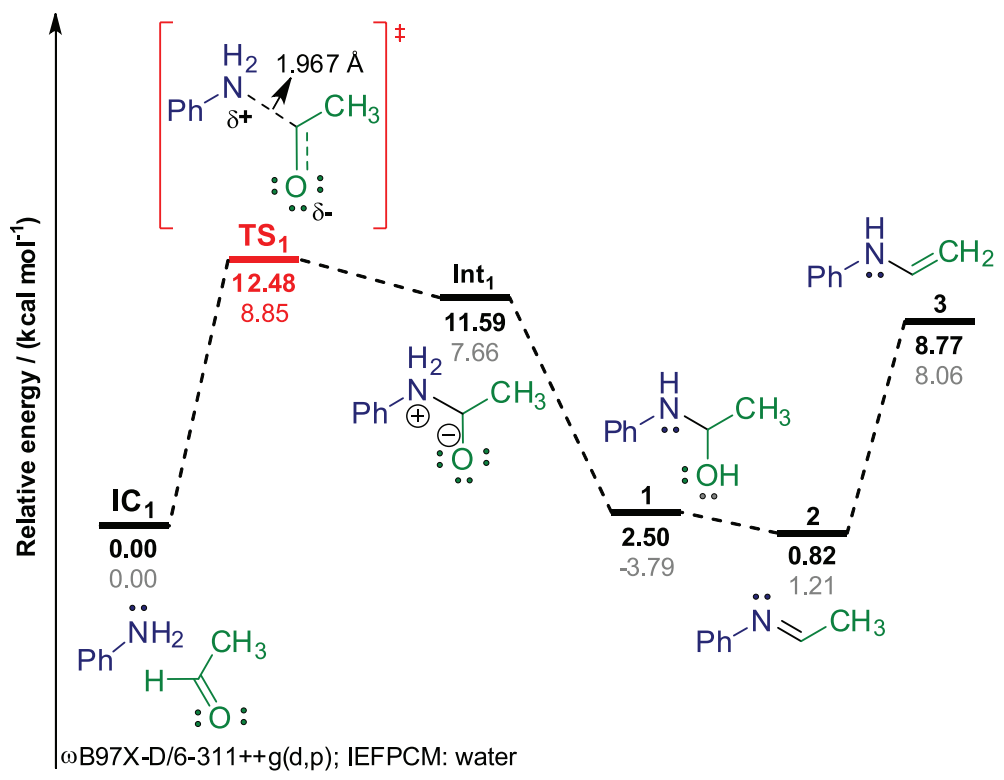

Figure 1. Energetic profile for enamimine (3) formation. The transition state is highlighted in red. The values are relative Gibbs free energy (bold) and enthalpy (light). All systems are solvated by five explicit water molecules (see optimized structures in SI section), in addition to implicit solvation.

by water molecules, using a supermolecule model 4 A. MC calculation on intermediate $\mathbf{4}$ revealed that the first solvation shell is composed by three water molecules arranged around the positive charges, establishing a net of hydrogen bonds. After DFT optimization, the relative energy of the zwitterion 4A drops to $8.5 \mathrm{kcal} \mathrm{mol}^{-1}$ (Figure 2). Transition state for the addition of enamine to the acetaldehyde under explicit microsolvation was optimized $\left(\mathbf{T S}_{4 \mathrm{~A}}\right)$, exhibiting $\Delta \mathrm{G}^{298}=15.4 \mathrm{kcal} \mathrm{mol}^{-1}$. In this saddle point, $2.070 \AA$ separates the two carbon involved in the forming bond. We also observed the exergonic formation $\left(-7.9 \mathrm{kcal} \mathrm{mol}^{-1}\right)$ of the neutral isomeric form $4 \mathrm{~B}$ with no charge separation when the supermolecule model was applied. This highlights the importance of using explicit microsolvation models in steps where charged sites, such as the zwitterions, and prototropisms may be involved.

Enamines have classically been used as nucleophiles. They have been employed for example in the formation of carbon-carbon bond in reactions such as Stork alkylation (when the electrophile is an alkyl halide or a Michael acceptor) or in Stork acylation (when the electrophile is an acyl halide). ${ }^{46-48}$ These reactions are similar to that suggested in step d. This step resembles the first step of the classical Prins-cyclization in which the alkene attacks the aldehyde under acid catalysis, as shown in Scheme 2. However, enamines are stronger nucleophiles due the non-bonded electron pair on nitrogen. Activation of the aldehyde by an acid is not required for the reaction sequence.

Two mechanistic possibilities emerge from step d, since the two possible intermediates showed in Scheme 3 were found: $\mathbf{4 A}$ and $\mathbf{4 B}$. $\mathbf{4 B}$ is more stable than $\mathbf{4 A}$

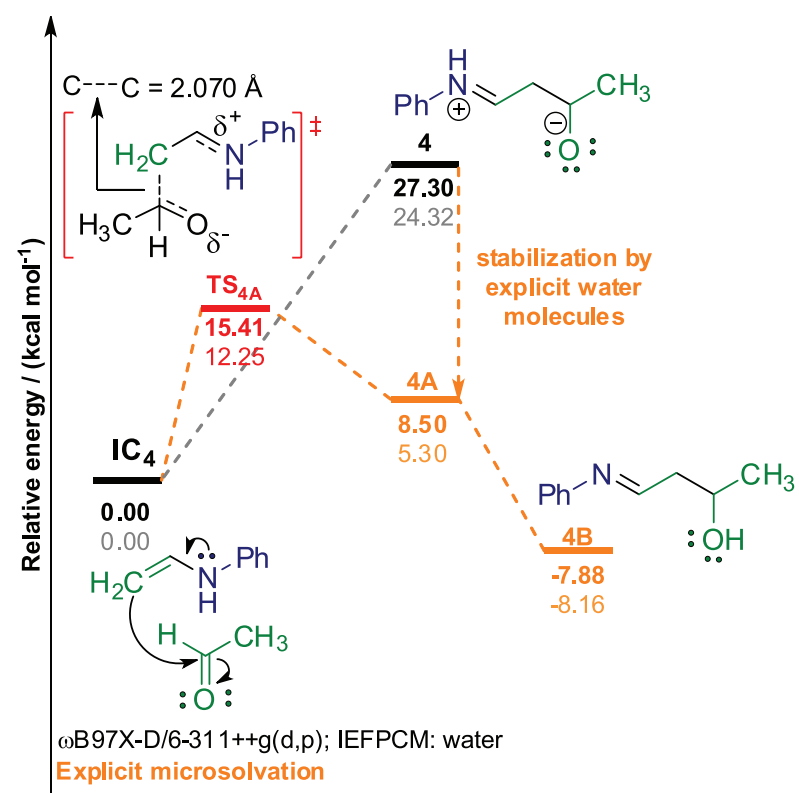

Figure 2. Gibbs free energy (bold) and enthalpy (light) change for step d considering only implicit solvation (in black) as well as explicit microsolvation (in orange). In red, transition state $\mathbf{T S}_{4 \mathrm{~A}}$ connecting $\mathbf{I C}_{4}$ and $4 \mathrm{~A}$ under supermolecule model approach with three water molecules.

by $16.4 \mathrm{kcal} \mathrm{mol}^{-1}$, meaning that in a process under equilibrium, the population distribution is shifted to the isomer with no charge separation. The same pattern was observed when zwitterion Int $\mathbf{1}_{\mathbf{1}}$ was compared to its neutral form, alkanolamine $\mathbf{1}$ (Figure 1). Even so, we investigated the two alternative pathways.

The consecutive step, formation of the 1,3-dioxane ring either from $\mathbf{4 A}$ or from $\mathbf{4 B}$, is a Prins-like cyclization. We calculated the relative energies of the possible 
diastereoisomers of the 4-phenylamino-1,3-dioxane. The bulkiest phenylamino substituent was fixed in the equatorial position. Consistent with experimental observation, ${ }^{28}$ the most stable isomer presents both methyl groups in equatorial positions (see SI section for energetic changes and geometry). Thus, the following intermediates and transition structures were computed considering the methyl groups only in the equatorial positions.

From the zwitterionic form $\mathbf{4 A}$ and using the implicit solvation model (see discussion below on the effect of explicit solvation) we could identify only a concerted pathway for formation of the 1,3-dioxane ring. An early transition state was calculated, $\mathbf{T S}_{5}$, with relative energy of $5.1 \mathrm{kcal} \mathrm{mol}^{-1}$, leading to an expressively exergonic formation of the desired 1,3-dioxane $5\left(\Delta \mathrm{G}^{298}=-37.0 \mathrm{kcal} \mathrm{mol}^{-1}\right)$, Figure 3. In this $\mathbf{T S}_{5}$, the forming bonds lengths are 2.219 and $2.538 \AA$. This highly exergonic behavior is probably due to the localized charges of the zwitterion $4 \mathrm{~A}$ being dispersed through the early concerted TS, affording the neutral product 5. A stepwise pathway could not be located using the exclusively implicit solvation model. Formation of a $\mathrm{C}-\mathrm{O}$ bond between the nucleophilic oxygen of $4 \mathrm{~A}$ and the $\mathrm{CHO}$ group of the aldehyde places the negatively charged oxygen of the aldehyde close to the positively charged carbon of the zwitterion. Consequently, the second $\mathrm{C}-\mathrm{O}$ bond would be formed by just an electrostatic attraction, without any barrier.

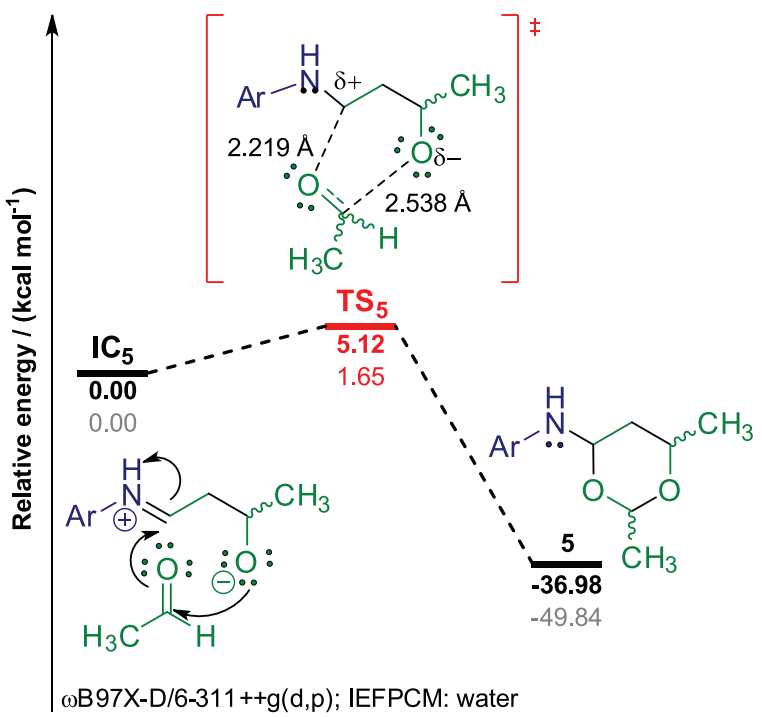

Figure 3. Energetic profile for step e considering exclusively implicit solvation. The values are relative Gibbs free energy (bold) and enthalpy (light), both in kcal mol-1.

Although $\mathbf{4 B}$ is much more stable than $\mathbf{4 A}$, we could not locate any transition structure or intermediate starting from it. Considering either a stepwise or a concerted pathway, the attack from $4 \mathbf{B}$ on the aldehyde would occur with the hydroxyl group, leading to a product (5) or intermediate with a positive charge located on the oxygen atom. None of these stationary points could be found as minimum energy geometry, warning us again about the importance of modelling this step with the supermolecule model.

Proceeding to the explicit microsolvation approach, maintaining the three water molecules of the precedent step, on the other hand, we could found only stepwise pathways for formation of the 1,3-dioxane $\mathbf{5}$, starting from either $4 \mathrm{~A}\left(\mathbf{I C}_{5 \mathrm{~A}}\right)$ or $\mathbf{4 B}\left(\mathbf{I C}_{5 \mathrm{~B}}\right)$. From $\mathbf{I C}_{5 \mathrm{~A}}$, due to the explicit water molecules, the net of hydrogen bonds stabilizes the system and an intermediate could be located. Following this pathway, we found an early transition structure $\mathbf{T S}_{5 \mathrm{~A}}$ connecting the reactants to the intermediate $\mathbf{I n t}_{5 \mathrm{~A}}$, with relative energies of 4.5 and $1.8 \mathrm{kcal} \mathrm{mol}^{-1}$, respectively. The intermediate $\mathbf{I n t}_{\mathbf{5 A}}$ then cyclizes to form the desired product, 5, releasing $27.7 \mathrm{kcal} \mathrm{mol}^{-1}$ energy (see SI section for optimized structures). No concerted possibility using this approach was found.

The non-ionic alternative pathway starts from $\mathbf{I C}_{\mathbf{5 B}}$. To find the stationary points considering explicit solvation, a relaxed scan was performed starting from the initial complex $\mathbf{I C}_{5 \mathrm{~B}}$, approximating the nucleophilic oxygen of 4B to the electrophilic carbon of the aldehyde. The results suggested a concerted proton transfer from $4 B$ to the aldehyde, through the net of hydrogen bonds, while the new $\mathrm{O}_{(\mathbf{A B})}-\mathrm{C}_{\text {(aldehyde) }}$ bond is formed, leading to the intermediate Int $_{\mathbf{5 B}}$, maintaining the electric neutrality along the process, releasing $6.7 \mathrm{kcal} \mathrm{mol}^{-1}$ in terms of Gibbs free energy. This intermediate resembles the unprecedented hemiacetal intermediate pointed by Yamabe et al..$^{27}$ in the classical Prins cyclization under acid catalysis.

Successive attempts to optimize the structure of the transition state connecting $\mathbf{I C}_{\mathbf{5 B}}$ to $\mathbf{I n t}_{\mathbf{5 B}}$ were not successful. In an effort to approach the transition structure we performed a two-dimensional relaxed scan connecting these two stationary minimum energy points. As a result, we obtained a contour plot, which helped to locate the minimum energy pathway (MEP) and an approximated geometry for the transition state (Figure S8, SI section). This transition state structure $\mathbf{T S 1}_{\mathbf{5 B}}$, which was fully optimized, has activation energy of $18.0 \mathrm{kcal} \mathrm{mol}^{-1}$. The computed IRC confirmed this structure as the transition structure connecting $\mathbf{I C}_{\mathbf{5 B}}$ to $\mathbf{I n t}_{\mathbf{5 B}}$.

To locate the $\mathbf{T S}$ for the cyclization step, we adopted the same strategy. Cyclization of $\mathbf{I n t}_{\mathbf{5 B}}$ occurs with concerted proton transfer from the nucleophilic oxygen to the nitrogen atom through the net of hydrogen bonds. Activation energy for this cyclization step is $13.0 \mathrm{kcal} \mathrm{mol}^{-1}$ relative to $\mathbf{I C}_{5 \mathrm{~B}}$ or $19.7 \mathrm{kcal} \mathrm{mol}^{-1}$ relative to the previous intermediate 
Int $_{\mathbf{5 B}}$. Formation of 5 is exergonic by $-13.7 \mathrm{kcal} \mathrm{mol}^{-1}$. The pathway starting from 4B involves only neutral species, in a mechanism with prototropisms, which maintain the electric neutrality of the system.

Since $4 \mathrm{~A}$ and $\mathbf{4 B}$ are interconvertible through an equilibrium process and since both pathways lead to the same product, $\mathbf{5}$, we compare both mechanistic possibilities on the same referential, as shown in Figure 4.

The highest energy points in both pathways have essentially the same energy, with a slightly lower energy for the transition structure $\mathbf{T S} \mathbf{1}_{\mathbf{5 B}}$, as compared to the corresponding $\mathbf{T S}_{5 \mathrm{~A}}$. However, $\mathbf{I C}_{5 \mathrm{~B}}$ is more stable than $\mathbf{I C}_{5 \mathrm{~A}}$ and thus we conclude that the pathway for the Prinslike cyclization most probably passes through the imine form $\mathbf{I C}_{\mathbf{5} \mathbf{B}}$, instead of the already proposed zwitterionic structure $\mathbf{I C}_{\mathbf{5 A}}$.

Therefore, step e of Scheme 3 is better described as a sequence of steps involving prototropism resulting in cyclization, leading to stationary points (minima and transients) with no ionic intermediate. This presents an alternative mechanism to formation of 1,3-dioxane ring via Prins cyclization in aqueous media and no catalyst. It is worth noting that these conclusions are only possible when using the supermolecule model, which allows for the prototropism.

To provide data for a further experimental confirmation of our hypothesis, we computed the KIE for different atoms directly involved in the cyclization for both pathways A and B, shown in Table 1. Primary KIE for hydrogen/deuterium is only possible in pathway B in which the nucleophilic sites are hydroxyl groups formed due the prototropism. Therefore, by using deuterium oxide, $\mathrm{D}_{2} \mathrm{O}$, instead of water as solvent, one could expect a change in the reaction rate constant if prototropism is part of the rate-determining step in the mechanism. Additionally, we also considered a possible secondary KIE by using deuterated acetaldehyde, $\mathrm{CH}_{3} \mathrm{CDO}$, since this hydrogen/deuterium is bonded to the electrophilic site. We found inverse KIE (below 1.00) for all transition states, which is expected when the planar carbon becomes tetrahedral. Isotopic labeling of acetaldehyde, either in the carbon $\left(\mathrm{CH}_{3}{ }^{13} \mathrm{CHO}\right)$ or the oxygen $\left(\mathrm{CH}_{3} \mathrm{CH}^{18} \mathrm{O}\right)$, should also provoke a change in the reaction rate constant, although less expressive.

Yet, aiming to confirm our computational model, we also calculated the cyclization step e considering benzenamine substituted in the para position of the aromatic ring with the nitro and the methoxyl groups. It has been shown that these substituents influence the experimental reaction time. ${ }^{28}$ The electron-withdrawing group $-\mathrm{NO}_{2}$ reduces the reaction time from 5 (for benzenamine) to $3 \mathrm{~h}$, suggesting reduction in the activation barrier. On other hand, the reaction time observed for 4-methoxybenzenamine is the same as that for the non-substituted benzenamine. Table 2 shows the relative energies for step e for the three species,

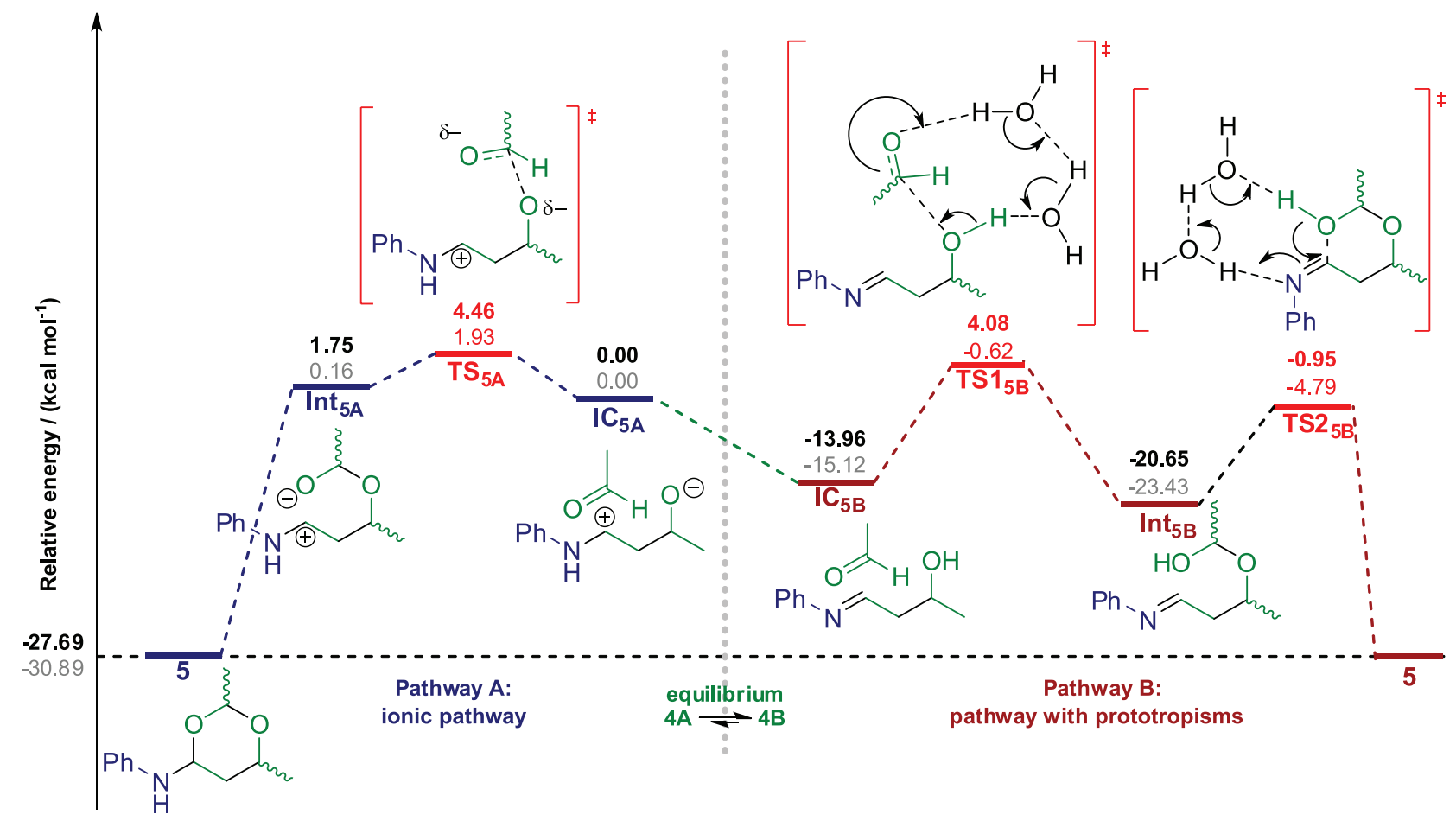

Figure 4. Comparison of pathways to form $\mathbf{5}$ starting from either $\mathbf{I C}_{5 \mathrm{~A}}$ or $\mathbf{I C}_{\mathbf{5 B}}$ with the supermolecule model approach. The water molecules are drawn in structures $\mathbf{T S 1} 1_{5 \mathbf{B}}$ and $\mathbf{T S} \mathbf{2}_{\mathbf{5 B}}$ to show the proton movement along the hydrogen bonds. All structures are equally solvated in the calculations. The values are relative Gibbs free energy (bold) and enthalpy (light), in $\mathrm{kcal} \mathrm{mol}^{-1}$. 
Table 1. Computed kinetic isotope effect, KIE, calculated with the ISOEFF98 software ${ }^{42}$

\begin{tabular}{lcccc}
\hline KIE & Experimental isotopic change & TS $_{5 \mathbf{A}}$ & TS1 $_{\text {5B }}$ & TS2 $_{\text {5B }}$ \\
\hline Primary, $\mathrm{k}_{\mathrm{H}} / \mathrm{k}_{\mathrm{D}}{ }^{\mathrm{a}}$ & $\mathbf{D}_{2} \mathrm{O}$ as solvent & not applied & 4.204 & 1.851 \\
Secondary, $\mathrm{k}_{\mathrm{H}} / \mathrm{k}_{\mathrm{D}}$ & $\mathrm{CH}_{3} \mathrm{CDO}$ & 0.919 & 0.794 & 0.913 \\
Carbon-13, $\mathrm{k}_{\mathrm{C}} / \mathrm{k}_{\mathrm{C}}{ }^{\mathrm{b}}$ & $\mathrm{CH}_{3}{ }^{13} \mathrm{CHO}$ & 1.032 & 1.021 & 1.004 \\
Oxygen-18, $\mathrm{k}_{\mathrm{O}} / \mathrm{k}^{*}{ }_{\mathrm{o}}^{\mathrm{c}}$ & $\mathrm{CH}_{3} \mathrm{CH}^{18} \mathrm{O}$ & 1.013 & 1.004 & 1.004 \\
\hline
\end{tabular}

${ }^{\mathrm{a}} \mathrm{k}_{\mathrm{H}} / \mathrm{k}_{\mathrm{D}}$ : primary kinetic isotopic effect for hydrogen/deuterium; ${ }^{b} \mathrm{k}_{\mathrm{C}} / \mathrm{k}^{*}{ }_{\mathrm{C}}$ : kinetic isotopic effect for carbon- $12 /$ carbon- 13 ; ${ }^{\mathrm{c}} \mathrm{k}_{\mathrm{O}} / \mathrm{k}^{*}{ }_{\mathrm{O}}$ : kinetic isotopic effect for oxygen-16/oxygen-18.

benzenamine $(\mathrm{R}=\mathrm{H})$, 4-nitrobenzenamine $\left(\mathrm{R}=\mathrm{NO}_{2}\right)$ and 4-methoxybenzenamine $\left(\mathrm{R}=\mathrm{OCH}_{3}\right)$.

Regarding the ionic pathway A, there is no substantial change in the energy values, except for the higher release of energy for formation of the final product $\mathbf{5}$ for the nitro substituent. The activation barriers for the three benzenamines have similar values, around $4 \mathrm{kcal} \mathrm{mol}^{-1}$ for Gibbs free energy and $2 \mathrm{kcal} \mathrm{mol}^{-1}$ for enthalpy data. According to our model, if the mechanism follows this ionic pathway, there should be no difference in the experimental reaction time for the three amines.

Considering the pathway with prototropisms, pathway B, the barriers for the nitro substituent are smaller when compared to the non-substituted benzenamine $\left(\mathbf{T S 1}_{\mathbf{5 B}}\right.$ and $\mathbf{T S} \mathbf{2}_{\mathbf{5 B}}$ ). The intermediate $\mathbf{I n t}_{\mathbf{5 B}}$ is also more stable. This agrees with the observation of reduced experimental reaction time. In contrast, there is no significant change for 4-methoxybenzenamine, also in agreement with the experimental results. The substituents in the para position are probably influencing the electrophilicity of the carbon attacked in the ring closure, represented by transition state $\mathbf{T S} \mathbf{2}_{\mathbf{5 B}}$. The nitro group withdraws electronic density by resonance effect $-\mathrm{R}$ and therefore enhances the electrophilicity of that carbon, diminishing the relative barrier. The methoxyl group presents the contrary effect $(+\mathrm{R})$. The Lewis structures associated to this donor character presents a trivalent positive oxygen atom, with little contribution to the resonance hybrid.

The mechanism with methylamine $(R=M e)$

To verify whether the data above are dependent on the type of amine employed in the reaction, particularly for the cyclization step, we also studied the reaction with an aliphatic amine (methylamine as model). All the calculations were repeated with methylamine. Energetic data were obtained after replacing the methyl for the phenyl group followed by geometry optimization. Figure 5 displays the relative Gibbs free energy and enthalpy before step e, the Prins-like cyclyzation. The structures with the added "_Me" index are the corresponding for those with the phenyl group discussed before.

No substantial change was found in the energetic profiles or in the geometries. Spatial configuration of the ancillary water molecules in the explicit microsolvation models exhibited patterns similar to those found with benzenamine.

Two points, however, called our attention. The first stage of step a, the addition of the amine to the aldehyde

Table 2. Free energy $(\Delta \mathrm{G})$ and enthalpy $(\Delta \mathrm{H})$ changes (both computed at $298 \mathrm{~K}$ and $1 \mathrm{~atm}$ ) along step e, for pathways A and B, for reaction with benzenamine, 4-nitrobenzenamine and 4-methoxybenzenamine

\begin{tabular}{|c|c|c|c|c|c|c|}
\hline \multirow[t]{2}{*}{ Structure } & \multicolumn{2}{|c|}{$\begin{array}{l}\text { Benzenamine } \\
(\mathrm{R}=\mathrm{H})\end{array}$} & \multicolumn{2}{|c|}{$\begin{array}{l}\text { 4-Nitrobenzenamine } \\
\qquad\left(\mathrm{R}=\mathrm{NO}_{2}\right)\end{array}$} & \multicolumn{2}{|c|}{$\begin{array}{l}\text { 4-Methoxybenzenamine } \\
\left(\mathrm{R}=\mathrm{OCH}_{3}\right)\end{array}$} \\
\hline & $\Delta \mathrm{G} /\left(\mathrm{kcal} \mathrm{mol}^{-1}\right)$ & $\Delta \mathrm{H} /\left(\mathrm{kcal} \mathrm{mol}^{-1}\right)$ & $\Delta \mathrm{G} /\left(\mathrm{kcal} \mathrm{mol}^{-1}\right)$ & $\Delta \mathrm{H} /\left(\mathrm{kcal} \mathrm{mol}^{-1}\right)$ & $\Delta \mathrm{G} /\left(\mathrm{kcal} \mathrm{mol}^{-1}\right)$ & $\Delta \mathrm{H} /\left(\mathrm{kcal} \mathrm{mol}^{-1}\right)$ \\
\hline $\mathbf{I C}_{5 \mathrm{~A}}$ & 0.00 & 0.00 & 0.00 & 0.00 & 0.00 & 0.00 \\
\hline $\mathbf{T S}_{5 \mathrm{~A}}$ & 4.46 & 1.93 & 4.22 & 2.01 & 4.08 & 2.36 \\
\hline Int $_{5 \mathrm{~A}}$ & 1.75 & 0.16 & 2.14 & -0.08 & 2.03 & 0.28 \\
\hline 5 & -27.69 & -30.89 & -34.42 & -36.98 & -27.20 & -28.87 \\
\hline $\mathrm{IC}_{5 \mathrm{~B}}$ & -16.96 & -15.12 & -21.23 & -18.42 & -17.28 & -15.24 \\
\hline $\mathrm{TS1}_{5 \mathrm{~B}}$ & 4.08 & -0.62 & 1.30 & -2.57 & 4.08 & -0.02 \\
\hline Int $_{5 \mathrm{~B}}$ & -20.65 & -23.43 & -24.13 & -25.36 & -20.43 & -22.64 \\
\hline $\mathbf{T S} 2_{5 \mathrm{~B}}$ & -0.95 & -4.79 & -2.73 & -5.99 & -1.51 & -4.35 \\
\hline 5 & -27.69 & -30.89 & -34.42 & -36.98 & -27.20 & -28.87 \\
\hline
\end{tabular}


$\omega B$ 97X-D/6-311++g(d,p); IEFPCM: water

step $\mathbf{a}, \mathbf{b}$ and $\mathbf{c}$ explicit microsolvation with 5 water molecules (MC)

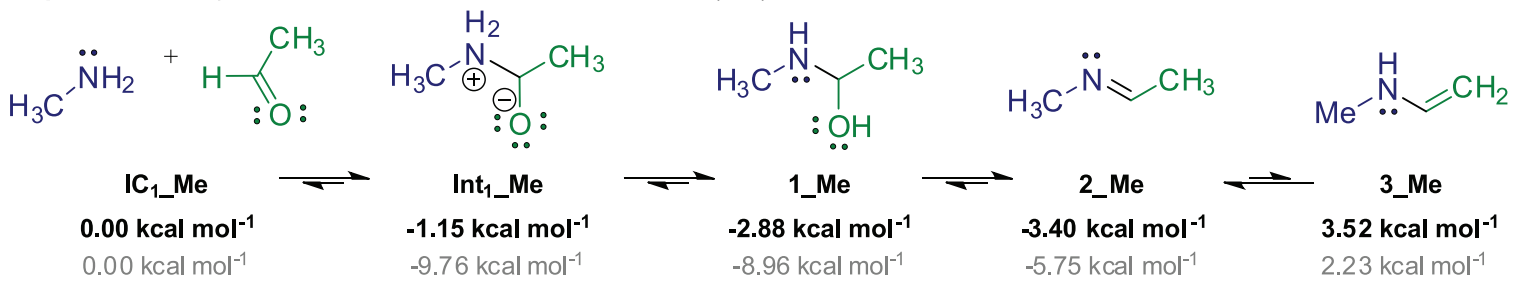

step d: explicit microsolvation

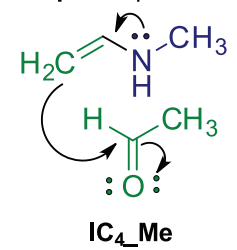

$0.00 \mathrm{kcal} \mathrm{mol}^{-1}$

$0.00 \mathrm{kcal} \mathrm{mol}^{-1}$
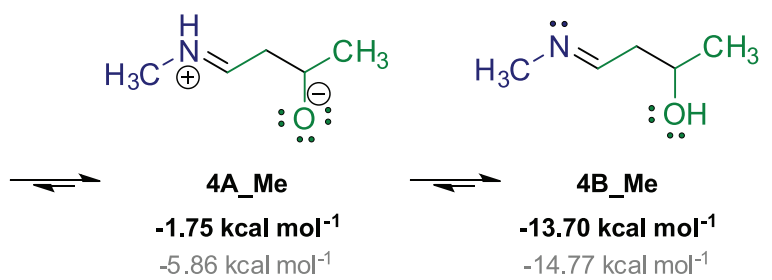

Figure 5. Thermodynamic data for steps a, b, c and d before Prins-like cyclization (step e) when methylamine is considered. The values are relative Gibbs free energy (bold) and enthalpy (light), both in $\mathrm{kcal} \mathrm{mol}^{-1}$.

to form the zwitterionic intermediate, is highly endergonic with benzenamine, while it is slightly exergonic with methylamine. As the nitrogen atom is tetravalent in the zwitterionic intermediates $\mathbf{I n t}_{\mathbf{1}}$ and $\mathbf{I n t}_{1} \_\mathbf{M e}$, dispersion of the formal positive charge through resonance effect is not possible. Thus, only inductive effect could stabilize the zwitterion. The methyl group $\left(\mathrm{C}_{\mathrm{sp} 3}\right)$ is a better electron donor through inductive effect than the phenyl group $\left(\mathrm{C}_{\mathrm{sp} 2}\right)$ when bonded to nitrogen atom. Possibly, this is the reason why formation of Int $\mathbf{I}_{\mathbf{1}} \mathbf{M e}$ is exergonic, while formation of $\mathbf{I n t}_{\mathbf{1}}$ is endergonic. Formation of the imine is correspondingly more exergonic with methylamine than with benzenamine. A similar behavior was found for the zwitterionic specie $\mathbf{4 A}$, which is much less stable in the case of benzenamine than with methylamine. Regardless of that, all neutral species are considerably more stable than ionic species.

The final step, cyclization, also showed an energetic profile similar to that found for benzenamine. The first transition state for the mechanism with prototropism is $3.4 \mathrm{kcal} \mathrm{mol}^{-1}$ more energetic than the transition state for the mechanism starting from the zwitterionic specie $\mathbf{4 A} \_\mathbf{M e}$, although the initial complex starting from $\mathbf{4 B}$ _Me is $16.0 \mathrm{kcal} \mathrm{mol}^{-1}$ more stable than $\mathbf{4 A} \mathbf{A}$ Me. Therefore, similar to the results with benzenamine, starting from $\mathrm{MeNH}_{2}$, the final step is more properly described as a non-ionic one, with prototropism starting from $\mathbf{4 B} \_\mathbf{M e}$ (see SI section for the detailed values).

\section{Conclusions}

An alternative reaction pathway without any ionic intermediate was found for 4-amino-1,3-dioxane synthesis via Prins cyclization by means of DFT approach using the $\omega$ B97X-D functional. Pathways with low activation energies were found when we applied the supermolecule model, considering the first solvation shell as that obtained from a Metropolis Monte Carlo calculation. The use of three equivalents of aldehyde is justified by the proposed mechanism: initial formation of the imine (2) consumes the first acetaldehyde molecule; the second is attacked by the enamine (3), leading to intermediates $\mathbf{4 A}$ and/or 4B; and the third involves in the Prins-like cyclization, affording the desired 1,3-dioxane product, 5. No catalyst was employed in the experimental setup composed only by amine, acetaldehyde and water. In this system, the enamine (3) acts as an alkene in the classical Prins reaction (Scheme 3). The stronger nucleophilicity of $\mathbf{3}$ is possibly responsible for the reaction occurring in absence of catalyst. In our calculations, explicit microsolvation was essential to model the several steps having proton transfer and zwitterionic species.

Our results show an alternative pathway for Prins cyclization when the unprecedented intermediate 4B was located, which is approximately $16 \mathrm{kcal} \mathrm{mol}^{-1}$ more stable than the zwitterionic isomer 4A. Regardless of the precursor considered for the Prins-like cyclization, 4A or 4B, we found only stepwise pathways for the cyclization step, using the explicit microsolvation approach. The relative energy values indicate 5 to be formed from $4 \mathrm{~B}$ in a sequence of steps involving prototropisms that maintain electrical neutrality during the course of the reaction. Intrinsic reaction coordinate simulation confirmed these unprecedented proposed transition states. Our calculated kinetic data (low activation barriers, in particular for the 
cyclization step) are in agreement with the experimental results in which 4-amino-1,3-dioxanes are obtained at $0-5{ }^{\circ} \mathrm{C}$ and low reaction times. The cyclization is considerably exergonic justifying the equilibrium shifted towards the 1,3-dioxane. In general, our computed values support the experimental observations and give details on the reaction pathway.

To confirm our computational model, we estimated carbon, oxygen and hydrogen (primary and secondary) kinetic isotope effect, providing reference data for an eventual further experiment. We also calculated 1,3-dioxane formation (step e) considering benzenamine substituted in the para position by electron-withdrawing (nitro) and electron-donating group (methoxyl) and compared with experimental results. Corroborating our hypothesis that the mechanism follows pathway $\mathrm{B}$, with prototropisms, this is the only pathway that yield results in line with the experimental data. The nitro group reduces the activation energy and increases the relative stability of intermediates, suggesting that the chemical equilibrium would be shifted towards formation of the final product. This aligns with the decreased experimental reaction time $(3 \mathrm{~h})$ compared to the non-substituted benzenamine $(5 \mathrm{~h})$. The 4-methoxybenzenamine, on the other hand, showed energetic profile similar to that found for the parent system, benzenamine. We also extended the study to aliphatic amine (methylamine) and found an energetic profile in general similar to that obtained with benzenamine, indicating that this reaction is not restricted to aromatic amines.

\section{Supplementary Information}

Supplementary information (computational details, Figures S1-S10, cartesian coordinates and energies of relevant stationary points) is available free of charge at http://jbcs.sbq.org.br as PDF file.

\section{Acknowledgments}

The authors acknowledge Conselho Nacional de Desenvolvimento Científico e Tecnológico (CNPq) and Fundação de Amparo à Pesquisa do Estado do Rio de Janeiro (FAPERJ) (grant E-26/201.302/2014 and grant E-26/203.001/2017) for providing research grants and financial support. Y. B. Kiran is thankful to University Grants Commission of India (UGC India) for funding (MRP-4595/14).

\section{References}

1. Chan, K.-P.; Ling, Y. H.; Loh, T.-P.; Chem. Commun. 2007, 939.
2. Greene, T. W.; Wuts, P. G. M.; Protective Groups in Organic Synthesis, $5^{\text {th }}$ ed.; Wiley: New York, USA, 2014.

3. Nkansah-Asare, S.; Schepmann, D.; Wünsch, B.; Bioorg. Med. Chem. 2017, 25, 2472.

4. Zhang, Q.; Cao, R.; Liu, A.; Lei, S.; Li, Y.; Yang, J.; Li, S.; Xiao, J.; Bioorg. Med. Chem. Lett. 2017, 27, 4061.

5. Tang, A. H.; Kirch, J. D.; Anesth. Analg. 1973, 52, 577.

6. Aepkers, M.; Wünsch, B.; Bioorg. Med. Chem. 2005, 13, 6836.

7. Bi, L.; Zhao, M.; Gu, K. L.; Wang, C.; Ju, J. F.; Peng, S. Q.; Bioorg. Med. Chem. 2008, 16, 1764.

8. Schmidt, M.; Ungvari, J.; Glode, J.; Dobner, B.; Langner, A.; Bioorg. Med. Chem. 2007, 15, 2283.

9. Kriewitz, O.; Ber. Dtsch. Chem. Ges. 1899, 32, 57.

10. Prins, H. J.; Chem. Weekbl. 1919, 16, 1072.

11. Prins, H. J.; Chem. Weekbl. 1919, 16, 1510.

12. Greco, S. J.; Fiorot, R. G.; Lacerda Jr., V.; dos Santos, R. B.; Aldrichimica Acta 2013, 46, 59.

13. Miles, R. B.; Davis, C. E.; Coates, R. M.; J. Org. Chem. 2006, $71,1493$.

14. Reddy, B. V. S.; Sreelatha, M.; Kishore, C.; Borkar, P.; Yadav, J. S.; Tetrahedron Lett. 2012, 53, 2748.

15. Kwon, M. S.; Woo, S. K.; Na, S. W.; Lee, E.; Angew. Chem., Int. Ed. 2008, 47, 1733.

16. Sundar, C. S.; Reddy, M. R.; Shridar, B.; Kumar, S. K.; Reddy, C. S.; Reddy, B. V. S.; Tetrahedron Lett. 2014, 55, 4236.

17. Reddy, L. M.; Reddy, V. V.; Satteyyanaidu, V.; Lakshmi, J. K.; Reddy, C. K.; Reddy, B. V. S.; Tetrahedron Lett. 2018, 59, 1084.

18. Launay, G. G.; Slawin, A. M. Z.; O’Hagan, D.; Beilstein J. Org. Chem. 2010, 6, DOI 10.3762/bjoc.6.41.

19. Lukin, A.; Bagnyukova, D.; Kalinchenkova, N.; Zhurilo, N.; Krasavin, M.; Tetrahedron Lett. 2016, 57, 3311.

20. Millán, A.; Smith, J. R.; Chen, J. L.-Y.; Aggarwal, V. K.; Angew. Chem., Int. Ed. 2016, 55, 2498.

21. Ahmed, N.; Konduru, N. K.; Beilstein J. Org. Chem. 2012, 8, 177.

22. Wang, J.; Crane, E. A.; Scheidt, K. A.; Org. Lett. 2011, 13, 3086.

23. Borkar, P.; van de Weghe, P.; Reddy, B. V. S.; Yadav, J. S.; Grée, R.; Chem. Commun. 2012, 48, 9316.

24. Breugst, M.; Grée, R.; Houk, K. N.; J. Org. Chem. 2013, 78, 9892.

25. Alder, R. W.; Harvey, J. N.; Oakley, M. T.; J. Am. Chem. Soc. 2002, 124, 4960.

26. Ogawa, Y.; Painter, P. P.; Tantillo, D. J.; Wender, P. A. J.; Org. Chem. 2013, 78, 104.

27. Yamabe, S.; Fukuda, T.; Yamazaki, S.; Beilstein J. Org. Chem. 2013, 9, 476.

28. Rambabu, G.; Reddy, B. P.; Kiran, Y. B.; Vijayakumar, V.; Barbosa, L. C. A.; Res. Chem. Intermed. 2015, 41, 8441.

29. Frisch, M. J.; Trucks, G. W.; Schlegel, H. B.; Scuseria, G. E.; Robb, M. A.; Cheeseman, J. R.; Scalmani, G.; Barone, V.; Mennucci, B.; Petersson, G. A.; Nakatsuji, H.; Caricato, M.; 
Li, X.; Hratchian, H. P.; Izmaylov, A. F.; Bloino, J.; Zheng, G.; Sonnenberg, J. L.; Hada, M.; Ehara, M.; Toyota, K.; Fukuda, R.; Hasegawa, J.; Ishida, M.; Nakajima, T.; Honda, Y.; Kitao, O.; Nakai, H.; Vreven, T.; Montgomery Jr., J. A.; Peralta, J. E.; Ogliaro, F.; Bearpark, M.; Heyd, J. J.; Brothers, E.; Kudin, K. N.; Staroverov, V. N.; Kobayashi, R.; Normand, J.; Raghavachari, K.; Rendell, A.; Burant, J. C.; Iyengar, S. S.; Tomasi, J.; Cossi, M.; Rega, N.; Millam, N. J.; Klene, M.; Knox, J. E.; Cross, J. B.; Bakken, V.; Adamo, C.; Jaramillo, J.; Gomperts, R.; Stratmann, R. E.; Yazyev, O.; Austin, A. J.; Cammi, R.; Pomelli, C.; Ochterski, J. W.; Martin, R. L.; Morokuma, K.; Zakrzewski, V. G.; Voth, G. A.; Salvador, P.; Dannenberg, J. J.; Dapprich, S.; Daniels, A. D.; Farkas, Ö.; Foresman, J. B.; Ortiz, J. V.; Cioslowski, J.; Fox, D. J.; Gaussian 09, Revision D.01; Gaussian Inc., Wallingford, CT, USA, 2009.

30. Chai, J.-D.; Head-Gordon, M.; Phys. Chem. Chem. Phys. 2008, $44,6615$.

31. Krishnan, R.; Binkley, J. S.; Seeger, R.; Pople, J. A.; J. Chem. Phys. 1980, 72, 650.

32. Costa, L. M.; Stoyanov, S. R.; Gusarov, S.; Tan, X.; Gray, M. R.; Stryker, J. M.; Tykwinski, R.; Carneiro, J. W. M.; Seidl, P. R.; Kovalenko, A.; Energy Fuels 2012, 26, 2727.

33. Nash, A.; Saßmannshausen, J.; Bozec, L.; Birch, H. L.; Leeuw, N. H.; J. Biomol. Struct. Dyn. 2017, 35, 1127.

34. Mennucci, B.; Cancès, E.; Tomasi, J.; J. Phys. Chem. 1997, $101,10506$.

35. Tomasi, J.; Mennucci, B.; Cancès, E.; J. Mol. Struct.: THEOCHEM 1999, 464, 211.
36. Allen, M. P.; Tildesley, D. J.; Computer Simulation of Liquids; Oxford University Press: New York, USA, 1987.

37. Breneman, C. M.; Wiberg, K. B.; J. Comput. Chem. 1990, 11, 361.

38. Coutinho, K.; Canuto, S.; DICE: A Monte Carlo Program for Liquid Simulation; University of São Paulo, São Paulo, Brazil, 1997.

39. Jorgensen, W. L.; Maxwell, D. S.; Tirado-Rives, J.; J. Am. Chem. Soc. 1996, 118, 11225.

40. McQuarrie, D. A.; Simon, J. D.; Physical Chemistry: A Molecular Approach; University Science Books: California, USA, 1997.

41. Fukui, K.; Acc. Chem. Res. 1981, 14, 363.

42. Anisimov, V.; Paneth, P.; J. Math. Chem. 1999, 26, 75.

43. Solís-Calero, C.; Ortega-Castro, J.; Hernández-Lagina, A.; Muñoz, F.; Theor. Chem. Acc. 2012, 131, 1263.

44. Ortega-Castro, J.; Adrover, M.; Frau, J.; Salvà, A.; Donoso, J.; Muñoz, F.; J. Phys. Chem. 2010, 114, 4634.

45. Pérez, P.; Toro-Labbé, A.; Theor. Chem. Acc. 2001, 105, 422.

46. Stork, G.; Brizzolara, A.; Landesman, H.; Szmuszkovicz, J.; Terrell, R.; J. Am. Chem. Soc. 1963, 85, 207.

47. Huang, W.-J.; Huang, C.-C.; Hsin, L.-W.; Tsai, Y.-M.; Lin, C.-T.; Lin J.-H.; Lee, S.-S.; Tetrahedron Lett. 2010, 51, 3062.

48. Kesel, A. J.; Biochem. Biophys. Res. Commun. 2003, 300, 799.

Submitted: January 23, 2019

Published online: April 29, 2019 